\title{
A oportunidade perdida em meio à revolução inesperada: a contribuição de Antonio Delfim Netto para a economia brasileira
}

Marcos Lisboa ${ }^{1}$

\section{Introdução}

Economia é arte estranha, que navega entre a academia, o debate sobre os rumos do país e a intervenção na política pública. Nenhum economista brasileiro trafegou por essas três áreas com tamanha influência como Antonio Delfim Netto.

Pode-se discordar de Delfim. Pode-se criticar muitas de suas escolhas na vida pública. A ditadura foi deplorável. Em vários momentos, discordei severamente das opções de política econômica que ele defendia com seu maneirismo usual. Mas não se pode deixar de ler Delfim.

O velho economista conhece seu ofício. Em sua longa carreira, boa parte fora da universidade, Delfim permaneceu atento à pesquisa acadêmica e a seus resultados sutis. Um dos seus esportes prediletos é criticar propostas ligeiras que desconhecem a complexidade dos casos particulares ou que são pouco embasadas pela evidência.

Mais de 60 anos depois, a sua tese de livre-docência ainda surpreende pela análise cuidadosa dos dados e dos efeitos inesperados da política de proteção do café durante a Primeira República.

- Agradeço a Zeina Abdel Latif, a Pedro Garcia Duarte e a Elvis Pereira por seus comentários. Como quase tudo que escrevo sobre história do pensamento, não é fácil saber o que é de minha autoria ou de meu irmão Samuel Pessôa. Alguns parágrafos da introdução foram originalmente publicados em um artigo que escrevi para o Brasil Journal. Trechos da seção sobe a história da Embrapa foram publicados em Lisboa (2019).

1 Presidente do Insper - Insper Instituto de Ensino e Pesquisa - Endereço: Rua Quatá, 300 - Vila Olímpia - São Paulo/SP - Brasil - CEP: 04546-042 - E-mail: marcos.lisboa@insper.edu.br. ORCiD: https://orcid.org/0000-0002-4067-9770.

Editor Responsável: Dante Mendes Aldrighi

(c) (i) (\$) Esta obra está licenciada com uma Licença Creative Commons Atribuição-Não Comercial 4.0 Internacional. 
Um trabalho como aquele não era esperado. O debate econômico no Brasil era dominado por teses como a da Cepal, em que havia muitas conjecturas e pouca análise empírica. "Romance em vez de economia", dizia uma professora nos anos 1950, como me contou Delfim.

Mas a USP daquele período se beneficiava de historiadores notáveis pelo estudo minucioso da evidência, como Sergio Buarque de Holanda e Alice Canabrava. ${ }^{2}$ Além disso, o Brasil da época recebeu a visita de muitos acadêmicos estrangeiros. Em São Paulo, eles ajudaram a construir a USP. No Rio de Janeiro, Eugênio Gudin, na FGV, convidava alguns dos melhores economistas de outros países que estudavam as razões do desenvolvimento econômico, como Jacob Viner.

A USP e a FGV foram duas notáveis exceções no estudo sobre economia naquele Brasil da curta república mediada por duas ditaduras. Ao contrário da tradição desenvolvimentista, ambas as escolas optavam por acompanhar a pesquisa em economia iniciada após o fim da Segunda Guerra nas principais universidades do exterior. E apenas na USP inicou-se uma agenda de pesquisa em que os modelos teóricos eram submetidos ao duro escrutínio dos dados.

A tese de Delfim foi o primeiro trabalho importante dessa tradição no Brasil. Mais tarde, Affonso Celso Pastore produziu estudos notáveis sobre a influência dos preços na produção agrícola e sobre a política monetária, ${ }^{3}$ e Carlos Langoni publicou um livro memorável sobre os determinantes da desigualdade de renda no Brasil. ${ }^{4}$ A breve experiência de uma pesquisa em economia que acompanhava o que se fazia no exterior, atenta aos desenvolvimentos da teoria e da análise dos dados, foi uma oportunidade perdida. Optamos pelas diversas narrativas que combinavam leituras criativas de Marx, Keynes e Kalecki para propor uma versão brasileira de economia, embaladas pelos descendentes da abordagem cepalina.

Em tempos destrambelhados, acreditávamos que podíamos inventar uma abordagem alternativa e peculiar para o desenvolvimento econômico. A leitura atabalhoada de muitos autores do passado era reforçada pela falta de análise cuidadosa dos dados disponíveis. Não havia como dar certo.

2 Em Lisboa (2019), conto um pouco da importância de Alice Canabrava no começo da FEA/USP. Para uma historiografia mais completa, ver Canabrava (1984).

3 Pessôa e Lisboa (2019) sistematizam a contribuição de Pastore.

4 Langoni (1974). 
Curiosamente, os economistas à esquerda e à direita concordavam no diagnóstico sobre as causas do nosso subdesenvolvimento. A narrativa dominante afirmava que a adoção de medidas de estímulo ao investimento privado nacional, apoiado pelo fortalecimento das empresas estatais, resultaria em crescimento econômico sustentável. A criatividade heterodoxa que prometeu desenvolvimento na maior parte do século XX não foi bem-sucedida, assim como não foi a sua repetição mais desastrada no governo Dilma.

Aos 92 anos, Delfim impressiona pelo vigor para o debate. Ele e Affonso Celso Pastore. Não obstante as suas muitas diferenças, ambos surpreendem por continuarem a estudar com cuidado a pesquisa acadêmica mais recente depois de carreiras tão longas e bem-sucedidas.

Os artigos que Delfim publicou na Folha de S.Paulo a partir da segunda metade dos anos 1980 são notáveis por anteciparem muitos dos problemas que nos afligiriam, tempos depois, em razão de um Congresso que distribuía benefícios sem saber muito bem quem pagaria a conta.

Em 2013, Zeina Latif e eu escrevemos sobre o rent-seeking na economia brasileira. ${ }^{5}$ Ao ler a coletânea de artigos de Delfim publicada há dois anos pela editora Três Estrelas, ${ }^{6}$ descubro que ele já escrevera sobre os caçadores de renda 25 anos antes, elegantemente traduzindo o termo para o português.

Sua erudição faz justiça à impressionante biblioteca que doou para a USP. Delfim conhece (e bem) de Marx a Keynes, além da teoria econômica mais recente.

Quando escrevi um artigo comentando a impressionante influência de Kenneth Arrow na economia, recebi um e-mail seu, gentil, como sempre, em que compartilhava a mesma admiração, mas considerava Keynes o maior do século. Virou uma brincadeira entre nós dois e, no fim, chegamos a um acordo em que consideramos Keynes o maior economista da primeira metade do século XX e Arrow o da segunda.

Delfim tem o mérito adicional da prosa sinuosa, elegante e sutil. A sua crítica parece um truque de mágico. Convida-nos a olhar sua mão direita, quando a surpresa vem pela esquerda. Com discrição paulista, tão

\footnotetext{
5 Esse artigo foi publicado um ano depois em um livro organizado por Simon Schwartsman; Lisboa e Latif (2014).

6 Delfim (2018).
} 
diferente dos arroubos cariocas, resta sempre a dúvida sobre quem o velho economista está a criticar. Em algumas de suas colunas, acho que fui a vítima. Não havia jeito. Terminava de lê-las rindo feito criança.

Este breve ensaio foi escrito para a sessão da ANPEC em homenagem aos 60 anos da defesa da tese de livre-docência de Delfim, "O Problema do Café no Brasil". O texto sistematiza algumas das principais contribuições de Delfim e, incidentalmente, comenta a oportunidade perdida de um país que optou pelo isolamento no comércio e na ciência. $\mathrm{O}$ economista que se tornou ministro acabou por colaborar com a profunda transformação no agronegócio brasileiro. A pesquisa acadêmica e a política pública entrelaçam a vida de Delfim e a história do país por caminhos inesperados.

A sua tese de história econômica sobre a política de valorização do café acabou por inaugurar uma agenda de pesquisa sobre a nossa agricultura que, com seu apoio no Ministério da Fazenda, contribuiu para a criação da Embrapa, centro de uma revolução na tecnologia da produção de alimentos.

A próxima seção resgata um pouco da história do pensamento econômico do século XX e a sua profunda transformação a partir da Segunda Guerra. Essa nova abordagem combinava modelos teóricos formais com precisas implicações que, nas circunstâncias adequadas, podem ser testadas empiricamente para rejeitar, ou não, a hipótese testada.

$\mathrm{Na}$ contramão de quase todas as escolas de economia do Brasil no período, a FEA/USP acompanhava a pesquisa acadêmica do exterior e formou uma geração de economistas fora do esquadro desenvolvimentista.

O primeiro deles foi Antonio Delfim Netto.

\section{Uma Nova Economia}

Houve uma revolução no método para estudar a economia a partir do fim da Segunda Guerra Mundial, com o desenvolvimento da econometria e da moderna abordagem abstrata na teoria. 
Até então, a economia era dominada por grandes abordagens interpretativas. Desde A Riqueza das Nações, de Adam Smith, os principais trabalhos se organizavam com base em alguns princípios abstratos em meio a proposição de leis gerais que procuravam dar conta de fatos estilizados e da tendência de longo prazo da produção e da renda.

Thomas Malthus propôs que a população tendia a crescer mais aceleradamente do que a produção de alimentos, o que levaria à pauperização da população. Muitos economistas, como David Ricardo, Karl Marx e John Stuart Mill, acreditavam que existia uma tendência decrescente da taxa de lucro, o que resultaria na estagnação da renda e da produção.

O debate teórico naquele período se dava pela contraposição de princípios abstratos, seja com as muitas versões da teoria do valor trabalho, de Ricardo e Marx, seja com a corrente austríaca e a sua teoria do capital. Todas essas abordagens, no entanto, fracassaram ao tentar propor uma teoria dos preços relativos que fosse consistente com a tese comum de que a taxa de lucro tenderia a se uniformizar nos diversos setores. ${ }^{7}$

Mesmo no começo do século XX, as principais contribuições em economia combinavam alguma ideia criativa com uma tentativa de construção de uma narrativa abstrata sobre o funcionamento de uma economia de mercado, da surpreendente teoria monetária de Knut Wicksell à contribuição repleta de argumentos inovadores de John Maynard Keynes sobre a interação entre os mercados de moeda, produção e emprego.

A revolução que se inicia a partir da Segunda Guerra adota um caminho diferente. Por um lado, a teoria econômica passa a se concentrar em proposições abstratas que podem ser logicamente derivadas de hipóteses precisamente delimitadas. Ao contrário da tradição clássica, essa abordagem não possui qualquer conteúdo empírico e não dialoga diretamente com os fatos observados.

Em que condições existe um equilíbrio competitivo em um modelo de equilíbrio geral? Existe um mecanismo de escolha social que satisfaça alguns princípios básicos, como racionalidade e completude? Como analisar a interação entre jogadores que sabem que suas decisões afetam o comportamento dos demais?

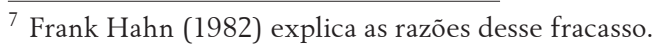


Esses resultados nada dizem sobre o mundo, afinal, resta saber em que medida os argumentos são consistentes com a evidência empírica. Além do mais, o notável desenvolvimento da teoria na segunda metade do século XX é repleta de abordagens radicalmente distintas. Modelos competitivos e não competitivos, jogos cooperativos e não cooperativos, racionalidade plena ou limitada são apenas alguns poucos exemplos da diversidade de temas e abordagens da economia daqueles anos.

Quase não havia princípios comuns que unificassem esses desenvolvimentos da teoria econômica, a não ser que fossem logicamente impecáveis. O ponto de partida poderia ser alguma intuição de Karl Marx ou de libertários economistas austríacos. Importava a demonstração dos teoremas.

Por outro lado, o desenvolvimento da econometria, tendo por base a seminal contribuição de Trygve Haavelmo, iniciou uma longa agenda de pesquisa sobre como desenvolver os modelos da estatística para estimar relações entre as variáveis econômicas, tema difícil, pois as escolhas individuais dependem das condições existentes.

A economia aplicada tenta saber como as pessoas reagem em situações diversas, frequentemente diferentes das que são observadas. Qual o impacto de uma reforma tributária sobre as decisões de investimento, por exemplo?

Esse tipo de pergunta requer análises contrafactuais, estimar o comportamento individual caso fossem outras as regras do jogo. O desenvolvimento da econometria nas décadas seguintes, em particular a agenda de pesquisa liderada por James Heckman, mostrou que os problemas são muito mais sutis do que se supunha para identificar as relações de causalidade. Além disso, a análise aplicada não pode prescindir de modelos teóricos e conjecturas precisas que possam ser rejeitadas pelos dados disponíveis. O método de pesquisa foi a grande revolução no pensamento econômico, com suas regras para construir modelos formais e o desenvolvimento de técnicas de estimação e de identificação para verificar a aderência das conjecturas aos testes empíricos.

A política fiscal expansionista pode auxiliar na recuperação da atividade econômica? Qual deve ser a prioridade do gasto em educação? Qual a eficácia de programas como o Bolsa Família em comparação, por exemplo, com a desoneração da cesta básica? Como regular um mercado complexo como o de energia? 
Essas são as típicas perguntas dessa agenda econômica e em todos os casos a resposta está circunscrita às circunstâncias. Economistas com visões diferentes utilizam as muitas variações dos modelos formais, as bases de dados disponíveis e as técnicas da econometria, que dependem do modelo teórico a ser testado, para contrapor seus argumentos.

Em muitos casos, a evidência indica alguns resultados predominantes, como a maior relevância da educação básica e do cuidado com a primeira infância para a formação das novas gerações, ou a maior eficácia das políticas de gasto público do que a tributação discricionária para a redução da desigualdade. Em outros temas, a evidência é menos conclusiva, como o papel da política fiscal durante as recessões.

A nova economia, porém, como as demais ciências, são herdeiras de David Hume e do ceticismo do iluminismo escocês. A indução permite apenas contrapor argumentos que sobrevivem com graus variados de incerteza à evidência disponível. Não há verdade, mas apenas argumentos que parecem sobreviver melhor aos testes empíricos.

Por essa razão, a economia moderna assiste a críticas recorrentes sobre as teses momentaneamente dominantes. Por mais robusta que seja a evidência, há frequentemente anomalias, casos particulares que vão na contramão do esperado e que estimulam novas abordagens. Argumentos inicialmente considerados heterodoxos eventualmente se revelam mais bem-sucedidos em dar conta dos fatos observados.

O modelo de utilidade esperada, por exemplo, permitiu notáveis avanços em economia aplicada, sobretudo a partir dos anos 1950. Desde cedo, no entanto, foram identificadas algumas circunstâncias em que o comportamento efetivo das pessoas desvia do previsto pelo modelo. O resultado foi a proliferação dos modelos de racionalidade limitada nas últimas décadas.

$\mathrm{Na}$ economia moderna, as teses heterodoxas de hoje podem se tornar a ortodoxia de amanhã. Para isso, porém, elas devem sobreviver ao rigor do método e dos testes empíricos. 


\section{A Velha USP, Delfim e o Problema do Café no Brasil}

O Brasil do século XX ignorou essa revolução do pensamento econômico. As diversas versões do desenvolvimentismo seguiam a velha abordagem narrativa da economia clássica. Cada grupo propunha uma interpretação sobre a economia brasileira e defendia seu receituário para superar o nosso atraso.

Por isso mesmo, a história do pensamento econômico destaca as muitas escolas de pensamento que existiam por aqui, cada uma com seu diagnóstico e proposta de política pública. ${ }^{8} \mathrm{O}$ convencimento ocorria pela retórica verbal da sedução, não pela retórica delimitada pelo método da economia moderna.

Houve, contudo, uma breve exceção. Durante cerca de duas décadas, entre meados de 1950 e 1970, a economia da FEA/USP destoava do resto do país. Um jovem grupo de economistas, alunos da historiadora Alice Canabrava e do econometrista Luiz Bueno, também associado ao IBRE/ FGV, tentava acompanhar a produção acadêmica feita no exterior, estudando os modelos formais e testando a sua aderência aos dados observados no Brasil.

Antonio Delfim Netto foi o primeiro grande economista dessa geração. Delfim foi assistente de Canabrava e submetido ao duro exercício de levantar os dados de arquivo sobre escravos do século XIX, como costuma relatar. A história feita por essa geração se conta com base em muita documentação e atenção às informações disponíveis.

Luiz Bueno, por sua vez, estudara séries de tempo e a microeconomia de Alfred Marshall. Seus alunos eram estimulados a ler o que havia de mais moderno em economia.

Delfim me contou que regularmente ele e seus colegas tiravam cópias dos artigos mais recentes publicados nas principais revistas acadêmicas para que fossem lidos e debatidos. Estudava-se também Popper e se sabia da necessidade de argumentos suficientemente precisos de modo que pudessem ser desmentidos pelos dados disponíveis.

8 Ver, por exemplo, Bielschowski (2004). 
Naqueles anos 1950, havia um quase consenso de que a agricultura representava o que havia de mais atrasado no país e que nosso desenvolvimento passava pela industrialização. A voz discordante era Eugênio Gudin, que enfatizava a importância da educação e do ordenamento institucional para que o país pudesse crescer. Ele era cético sobre os esforços da política pública de estimular o desenvolvimento da indústria.

Em um encontro na Associação Comercial em meados daquela década, Gudin comentou com Delfim que montar e desmontar carros era fácil. Difícil mesmo seria domesticar a agricultura tropical, algo que ninguém havia feito.

Gudin, porém, era de outra geração e defendia uma narrativa, e nisso não se diferenciava dos desenvolvimentistas bem mais jovens da sua época. ${ }^{9}$ Ele conhecia mais o pensamento econômico do que os demais, mas, como eles, não acompanhara o surgimento das técnicas de avaliação empírica para testar conjecturas.

Delfim, por outro lado, conhecia a teoria e a econometria da época e estava a estudar justamente o setor cafeeiro no Brasil, que durante décadas fora o centro da política econômica. Os muitos estudos de Delfim naquela década resultaram na sua tese de livre-docência, O Problema do Café no Brasil.

Trata-se de um trabalho ainda hoje impressionante. Delfim, discípulo de Canabrava, mergulhou nos documentos de época e nos dados disponíveis para entender a história do setor cafeicultor, a política de valorização do produto na Primeira República e as suas repercussões. Além disso, aluno de Bueno, utilizou as técnicas de séries de tempo para estimar os impactos inesperados da política pública para proteger a produção cafeeira.

Na transição entre os séculos XIX e XX, o café era o nosso principal produto de exportação. $\mathrm{O}$ mercado livre, no entanto, acabava resultando em ciclos econômicos que poderiam durar alguns anos. O café demora a dar frutos e, dada a relevância do Brasil no mercado mundial, a produção excessiva resultava em preços baixos, afetando o câmbio e a economia nacional.

9 Mais de 20 anos depois da conjectura de Gudin, Carlos Langoni (1974) realizou um trabalho minucioso com microdados em que estimou o impacto da educação sobre a distribuição de renda. 
A importância da produção cafeeira na economia local induziu a pressão por políticas públicas de valorização do produto no mercado externo, que começaram com o Convênio de Taubaté e que se tornaram permanentes a partir da presidência de Arthur Bernardes (1922-1926). O objetivo era garantir que as nossas exportações não resultassem em baixos preços no mercado externo.

A principal conclusão de Delfim é que essa política de valorização do nosso principal produto de exportação acabou sendo um tiro no pé. A tentativa de proteger os cafeicultores foi a sua ruína, além de prejudicar o desenvolvimento do país.

O livro de Delfim revela fino conhecimento da economia da época ao analisar o período. A política pública, por exemplo, salvava os cafeicultores ineficientes ao tentar preservar a capacidade de produção do setor. Se produtores falissem, no entanto, os meios de produção continuariam a existir, podendo ser adquiridos por melhores gestores. Proteger a produção de café não deveria significar proteger os fazendeiros.

Cabe mencionar que atualmente a evidência indica que parte relevante da diferença de produtividade entre os países ricos e pobres decorre precisamente da intervenção pública que protege produtores ineficientes e impede que seus ativos sejam utilizados por gestores mais produtivos. ${ }^{10}$

Delfim também sabia de microeconomia e comentou os diferentes modelos de relação entre lavradores e proprietários, descrevendo suas formas de remuneração e os impactos sobre o comportamento dos produtores em decorrência das regras de divisão de risco.

A sua tese analisa os impactos macroeconômicos das intervenções no mercado de café sobre a taxa de câmbio e a inflação, que terminam por cobrar de forma disseminada da sociedade os benefícios transferidos aos cafeicultores.

A herança da econometria inicialmente aprendida com Bueno aparece nas regressões sobre o impacto deletério das intervenções sobre o preço do café. Para que a política de valorização fosse sustentável, a demanda internacional deveria ser pouco sensível aos preços, a concorrência não deveria reagir e o câmbio deveria ficar estável apesar do volume de divisas, tudo

${ }^{10}$ Para uma resenha sobre essa agenda de pesquisa, ver Restuccia e Rogerson (2017). 
somado para que a receita pública com tarifas subisse o suficiente para cobrir o custo da dívida pública que financiaria a intervenção.

Faltou combinar com a realidade. Os dados analisados por Delfim mostravam que cada etapa do argumento não sobrevivia aos testes empíricos. Além disso, ele sabia que era desastre anunciado tratar preços e quantidade como variáveis independentes e que a taxa de câmbio real se ajustava aos fluxos externos por bem, com valorização da taxa nominal, ou por mal, via inflação.

A análise de Delfim sobre a intervenção brasileira no mercado mundial de café na Primeira República guarda semelhança com o modelo de organização industrial em que há uma firma líder e muitas firmas seguidoras. A líder considera a produção das menores como dada e maximiza seu lucro para atender a demanda restante.

A política que buscava maximizar a receita a cada ano, observou Delfim, resultava em uma solução ineficiente a longo prazo. A política de valorização garantia maior preço no curto prazo, porém estimulava o aumento da produção e a entrada de novos produtores em outros países, prejudicando, a longo prazo, o setor cafeeiro local.

Delfim não formula precisamente, mas fica claro que a solução deveria utilizar um modelo de otimização intertemporal. Nada mal, dado que até então apenas Frank Ramsey havia tentado resolver o problema de escolha intertemporal em economia, modelo que apenas nos anos 1950 começou a ser mais conhecido.

Em 1968, Edmar Bacha propôs um ajuste nesse cálculo. ${ }^{11}$ A política pública deveria maximizar o valor presente da renda per capita decorrente da política de valorização do café, não o fluxo anual de receita. Nesse caso, possivelmente o seu preço desejável no curto prazo seria um pouco maior do que na solução proposta por Delfim. Os maiores recursos arrecadados inicialmente permitiriam ao país investir em outras atividades rentáveis que compensassem a queda da receita futura das exportações de café.

11 Devo a Samuel Pessôa a referência a esse artigo, que foi republicado, com revisões, em Bacha (1976). 
Curioso constatar quanto o jovem Delfim, há sessenta anos, se divertia com os exercícios de matemática, logo ele que, décadas depois, criticaria com a fina ironia e a elegância de sempre os economistas que abusam do formalismo.

Havia, porém, um problema real, como ele aponta. As flutuações da economia decorrente do peso do café na pauta exportadora resultavam em volatilidade dos recursos fiscais. No começo do século passado, as tarifas de comércio exterior eram parte relevante da receita pública.

Delfim não tratou do tema, mas hoje sabemos que uma solução seria um fundo de estabilização fiscal, como o faz, por exemplo, o Chile no caso do cobre. O surpreendente é que Eugênio Gudin já tinha analisado cuidadosamente, em 1943, como a dependência de poucos produtos primários para exportação amplia a volatilidade da economia e de que forma a política pública poderia intervir para suavizar os ciclos. ${ }^{12}$

\section{Delfim e a Revolução da Agricultura}

A história da tese sobre o "Problema do Café" não termina com a sua publicação. Nos anos seguintes, Delfim formou uma geração e incentivou a continuação da pesquisa sobre agricultura no Brasil.

$\mathrm{Na}$ época, o pensamento econômico acreditava que a agricultura era herança indesejada do passado. O setor atrasado não reagiria aos preços de mercado, que poderiam aumentar ou diminuir sem que isso alterasse a quantidade produzida de alimentos. Além disso, haveria excesso de trabalhadores no campo, em boa parte improdutivos. No jargão da profissão, a produtividade marginal do trabalho no campo seria nula, e seria possível reduzir o total de agricultores, segundo alguns economistas, sem que isso alterasse a produção agrícola.

Desde os anos 1940, porém, o economista Theodore Schultz discordava da tese dominante. Embasado por muitos estudos microeconômicos, ele mostrou que a agricultura reagia aos preços de mercado como os demais

${ }^{12}$ Gudin (1972, volume 2, capítulo X). 
setores da economia. Mais ainda, Schultz criticou a tese de que a agricultura dos países pobres tinha trabalhadores em excesso, improdutivos. A solidez do seu argumento surpreende meio século depois.

A boa estatística requer testar hipóteses por meio de grupos de controle, verificando-se o que ocorreria em casos assemelhados, a menos da mudança de um único fator. Na medicina moderna, um grupo homogêneo de pessoas é separado aleatoriamente em dois grupos; um recebe a droga, o segundo recebe placebo. Assim, pode-se estimar o impacto da droga sobre os pacientes.

Nas últimas décadas, testes semelhantes passaram a ser feitos na microeconomia, mas em muitos casos importantes isto não é possível. Eventualmente, porém, as circunstâncias permitem testar conjecturas como nos experimentos. Acidentes inesperados afetam comunidades de forma diferente, permitindo realizar os testes desejados.

No começo dos anos 1960, Schultz observou que a gripe espanhola tinha resultado em mortalidade variada nas diversas regiões da Índia no fim da década de 1910. Essa doença devastadora matou parte da população, muitas vezes entre $4 \%$ e $8 \%$, mas não deixou sequelas na população sobrevivente, nem nos animais ou nas plantas.

Comparando os dados nos anos anteriores e posteriores à devastação provocada pela epidemia, porém, Schultz constatou que a produção agrícola caiu na mesma proporção da redução da população. Ao contrário da tese dominante, não havia trabalhadores em excesso na agricultura. Quanto maior a mortalidade de trabalhadores rurais, maior a queda da produção de alimentos.

Os economistas da USP nos anos 1960 tinham uma agenda de pesquisa semelhante à de Schultz. Em meados dos anos 1960, Delfim liderou um grupo de pesquisa sobre a economia agrícola no Brasil. Seria verdade que a produção de alimentos não reagiria aos preços?

Affonso Celso Pastore fez parte desse grupo de pesquisa que, com base em dados agregados, mostrou que a tese dominante parecia pouco robusta. Aparentemente, a produção agrícola reagiria aos preços de mercado como qualquer outro setor. 
Pastore, como Delfim, fora assistente de Canabrava, aluno de Bueno e conhecia os trabalhos de Schultz. Em 1968, ele pediu dispensa do seu cargo no Ministério da Fazenda para verificar, utilizando dados desagregados, se a produção agricultura não responderia aos preços de mercado no Brasil.

Em sua tese de doutorado, Pastore analisou os resultados a partir das bases de dados disponíveis com um cuidado impressionante em uma época que ainda desconhecia os testes de causalidade de Granger. Depois de exaustivos testes, ele concluiu que a visão convencional estava equivocada. A produção agrícola reagia aos preços de mercado como os demais setores da economia.

Pouco antes, Delfim iniciara uma segunda militância, conduzindo a política econômica como ministro da Fazenda.

No começo dos anos 1960, o país vivenciara a ressaca da expansão desenvolvimentista da década anterior, com anos de baixo crescimento, inflação elevada e crise tanto nas contas públicas quanto no balanço de pagamentos. A partir do governo Castello Branco (1964-1967), a política econômica liderada por Roberto Campos e Octavio Bulhões procurou equilibrar as contas públicas. Além disso, foi iniciada uma extensa agenda de reformas institucionais que, em meio a um ciclo de expansão do comércio mundial, permitiu o notável crescimento econômico do fim dos anos 1960 e começo da década seguinte. ${ }^{13}$

Em sua gestão no Ministério da Fazenda, entre 1967 e 1974, Delfim teve o mérito de liderar uma política bem-sucedida de promoção das exportações em um momento de expansão do comércio mundial. ${ }^{14}$

A economia política que se desenvolvera a partir da produção cafeeira fora lição aprendida. Como o produto era importante, tentava-se proteger a renda dos fazendeiros, mas isso tinha efeitos colaterais sobre o restante da economia, prejudicando o desenvolvimento dos demais setores. Para o ministro, era preciso diversificar as nossas exportações. Trata-se de um dos maiores legados de Delfim e, indevidamente, pouco reconhecido.

${ }^{13}$ Para uma análise da expansão da economia brasileira nesse período, ver Veloso, Vilella e Giambiagi (2008).

${ }^{14}$ Em um artigo escrito com Nathaniel Leff (1966), Delfim mostra que uma política de substituição de importações pode resultar em maior crescimento, mas com frequência fracassa em resolver o déficit no balanço de pagamentos. 
O economista-ministro sabia que para exportar precisava importar, entendia de câmbio e de macroeconomia, além de saber da relevância da produtividade para viabilizar as exportações e financiar o desenvolvimento econômico.

Foram muitas as medidas adotadas, como a de permitir importar componentes para exportar produtos. Nossa pauta se diversificou e o Brasil viveu seu milagre econômico, com a ajuda essencial tanto das reformas institucionais e do ajuste fiscal promovido antes por Campos e Bulhões quanto do notável ciclo de expansão de commodities na virada dos anos 60 para 70 .

Há muitas importantes histórias associadas a Delfim nesse período, como seu apoio à pesquisa sobre as razões da baixa produtividade da nossa agricultura. Várias delas aprendi com Eliseu Alves, que se juntou a um grupo de economistas e técnicos agrícolas, liderados pelo sociólogo José Pastore, para entender as razões do fracasso por aqui do modelo de extensão rural adotado nos EUA para disseminar as melhores técnicas agrícolas e aumentar a produtividade.

Eliseu Alves surpreende pela sisudez das palavras, lógica dos argumentos e profundidade das conclusões. Tudo isso em meio a uma ética protestante em que a crença em Deus convive em pé de igualdade com o respeito à ciência. Esse homem, de palavras simples e raciocínio impecável, é parcimonioso ao falar dos outros. Menos de Delfim, a quem enaltece pela sua importância para a revolução agrícola iniciada nos anos 1970.

$\mathrm{Na}$ época, existiam diversos institutos públicos dedicados à pesquisa científica para melhorar a produtividade agrícola no Brasil, como o Instituto Agronômico de Campinas e a Escola Superior de Agricultura "Luiz de Queiroz", a ESALQ, que se beneficiaram da imigração de muitos professores europeus após a Segunda Guerra Mundial. Além disso, Nelson Rockefeller e a Fundação Ford financiavam programas para desenvolver a produtividade da agricultura no Brasil.

A baixa produtividade da agricultura era atribuída ao pouco acesso dos agricultores às tecnologias modernas de produção. Por essa razão, optou-se por adotar o modelo de extensão rural utilizado nos Estados Unidos, que levava técnicos para auxiliar os agricultores no manejo da sua produção. 
No fim dos anos 1960, porém, Eliseu Alves documentou em sua tese de mestrado que o modelo de extensão rural fracassara em aumentar a produtividade da produção agrícola. $\mathrm{O}$ problema não parecia ser o pouco acesso às técnicas disponíveis, mas sim a falta de conhecimento para lidar com os desafios da agricultura tropical, como Eugênio Gudin já tinha alertado nos anos 1950.

Delfim Netto, ministro da Fazenda, apoiou a pesquisa para expandir a produção na agricultura e a diversificação da pauta de exportações. Cinco anos depois, o ministro da Agricultura do governo Médici, Luiz Fernando Cirne Lima, organizou um grupo de trabalho para identificar as razões da baixa produtividade da produção agrícola no Brasil. Esse grupo foi liderado por José Pastore e dele participaram Eliseu Alves, Carlos Langoni, Affonso Pastore, entre outros.

A conclusão foi que não havia técnicas adequadas para o nosso clima. O governo deveria estimular a formação de pesquisadores nas melhores universidades do Brasil e do exterior. Em contato com os problemas específicos encontrados pelos agricultores nas diversas regiões, a pesquisa científica deveria identificar as vantagens comparativas locais e as intervenções necessárias para aumentar a produtividade.

O resultado foi a criação da Embrapa em 1973. José Irineu Cabral foi escolhido para presidir a empresa, liderando a sua implementação. Eliseu Alves tornou-se o diretor responsável pela gestão de pessoas e iniciou um extenso programa de concessão de bolsas de estudos para pós-graduação, mais de 2 mil alunos em 12 anos, boa parte no exterior.

Criticado pelo tamanho do programa, Eliseu comentava: "Formar técnicos é como dar tiro de cartucheira, um grão de chumbo vai atingir a caça". A cartucheira libera muitos pedaços de chumbo que se espalham na direção do tiro, sendo improvável que um deles não atinja o alvo. Com tantos técnicos sendo treinados, era inevitável, acreditava Eliseu, que alguns deveriam se tornar pesquisadores relevantes para modernizar a nossa agricultura.

Naquela década, Eliseu Alves e Affonso Pastore produziram diversos trabalhos acadêmicos documentando os dados sobre o crescimento da agricultura desde o começo do século. Na contramão da visão dominante, 
ambos argumentaram que os ganhos de produtividade eram induzidos pelas condições de mercado.

O fim dessa história é bem conhecido. Novas técnicas de produção permitiram a expansão da agricultura tropical, como a inesperada produção de soja no Centro-Oeste e do café no cerrado de Minas Gerais. Nas décadas seguintes, a produtividade da agricultura brasileira aumentou mais de $3 \%$ ao ano, permitindo o barateamento dos alimentos e a diversificação da pauta de exportações.

Apesar do sucesso da agenda de reformas iniciadas pelo governo Castello Branco e da diversificação da pauta de exportações conduzida por Delfim, a partir do choque do petróleo optamos, no governo Geisel, por retomar a velha agenda desenvolvimentista e fomos ladeira abaixo em meio a muitas experiências heterodoxas. O Brasil se fechou ao comércio exterior e passamos a inventar que, por aqui, a economia seria diferente. O país se financiou com empréstimos no exterior e foi penalizado com o forte aumento dos juros realizado pelo Banco Central americano no fim da década para controlar a inflação. O resultado foi semelhante à crise dos anos 1960, com inflação elevada, desaceleração da atividade econômica e crise tanto das contas públicas quanto do balanço de pagamentos.

Delfim foi ministro do Planejamento do governo Figueiredo entre 1979 e 1985 e tentou controlar os desequilíbrios macroeconômicos por meio de um plano heterodoxo em que prefixou a taxa de câmbio e a correção monetária. Seu fracasso contribuiu para a maior crise da nossa história.

Para seu mérito, nos anos seguintes, ele e sua equipe fizeram correções de rumo e a economia começou a se recuperar, ainda que com uma inflação disfuncional. O que já era ruim no governo Figueiredo, no entanto, se tornaria muito pior depois com uma sequência de planos heterodoxos fracassados que desestruturou a economia brasileira e resultou em anos de baixo crescimento econômico. 


\section{Oportunidade Perdida}

Em artigo recente, escrito em homenagem aos 80 anos de Affonso Celso Pastore, contei um pouco da notável história da FEA/USP em meados do século passado. ${ }^{15}$ A geração formada naqueles anos estudava as novidades da teoria econômica assim como as novas técnicas da econometria.

Delfim foi o primeiro grande economista daquela geração e Affonso Celso Pastore foi o seu melhor aluno, escrevendo trabalhos notáveis em que tratava os dados com rigor monástico e utilizava as técnicas de séries de tempo para estudar temas tão diversos como a influência dos preços na produção agrícola e a política monetária.

Delfim é homem de palavras gentis e jeito maroto. Conversa muito e cuida dos argumentos para garantir a civilidade. Com sua habilidade sinuosa, sempre descobre como superar obstáculos e envolver os demais. Suas histórias são permeadas de observações que despertam a graça e a simpatia dos ouvintes, em meio a críticas que despontam ocasionalmente, desde que o ouvido seja apurado.

Durante algumas décadas após 1950, Delfim, Pastore e alguns poucos economistas brasileiros, como Carlos Langoni e Edmar Bacha, acompanhavam a fronteira do pensamento econômico desenvolvida no exterior. ${ }^{16}$

Eles conheciam o que de melhor se fazia em teoria na época e as novidades da econometria. Testavam hipóteses e tratavam os dados com o cuidado de um investigador, preocupados em saber exatamente o que ocorreu, em vez da atitude usual do economista que, como um pregador, seleciona as evidências para confirmar suas profecias.

Infelizmente, foi uma oportunidade perdida. A divergência política acabou por dividir a nossa profissão e a imensa maioria passou a achar que o importante era desacreditar o outro lado. A moderna economia que aqueles poucos faziam acabou ofuscada pelo confronto decorrente da trágica ditadura.

15 Lisboa (2019).

${ }^{16}$ Há uma ponte surpreendente que une os trabalhos de Pastore e de Langoni (1974): a imensa contribuição de Theodore Schultz. Além dos seus trabalhos sobre a agricultura, que estimularam a pesquisa de Pastore, ele identificou a relevância da educação para a produtividade e a remuneração dos trabalhadores, que denominou de Capital Humano. Schultz orientou da tese de doutorado de Carlos Langoni. 
O resultado foi o naufrágio da velha USP, que terminou por sucumbir à abordagem clássica que dominava a economia brasileira. A política, por mais violenta que seja, não deveria impedir o debate aberto. Optamos pelo obscurantismo e pagamos um preço alto ainda hoje.

Para os jovens economistas, recomendo que leiam os trabalhos que Delfim, Pastore e Langoni faziam há meio século, além do notável debate entre Bacha e Pastore sobre temas da política econômica no começo dos anos 1970, que surpreende pelo cuidado com a avaliação empírica que permite o aprendizado. ${ }^{17} \mathrm{O}$ rigor com que utilizavam a teoria e os dados em tempos de computadores lentos são de cair o queixo. A nova geração tem como corriqueiro o que no caso deles era feito extraordinário.

Leiam Delfim e apreciem sua agenda meticulosa para entender um problema e identificar a intervenção mais eficaz para resolvê-lo. Foram 30 anos entre as pesquisas cuidadosas e a sua contribuição para a adoção da política pública que revolucionou a nossa agricultura.

Nos últimos anos, aproximei-me de Delfim. Divergimos menos do que pensávamos, exceto sobre a política daqueles trágicos anos da ditadura, que deixamos na antessala para ser melhor avaliada com a paciência da longa história.

Pela sua contribuição para o pensamento econômico brasileiro e a revolução da agricultura tropical, Antonio Delfim Netto merece nossa gratidão e nossa admiração.

\section{Referências}

Bacha, E. (1968): “A Política Cafeeira do Brasil, 1952/1967”. Revista Dados, 5. Reproduzido com correções em: Mitos de uma Década, Werner Baer (organizador). Editora Paz e Terra, 1976.

Canabrava, A., org. (1984): História da Faculdade de Economia e Administração da Universidade de São Paulo, 1946-1981. São Paulo: FEA/USP.

Delfim Netto, A. (1959): O Problema do Café no Brasil. Editora Unesp, terceira edição, 2009.

Delfim Netto, A. (2018): O Animal Econômico. Editora Três Estrelas.

17 Esse debate é sistematizado em Pessôa e Lisboa (2019). 
Gudin, E. (1943): Princípios de Economia Monetária. Editora Agir, 8 edição, 1972.

Hahn, F. (1982): “The neo-Ricardians". Cambridge Journal of Economics; 6(4).

Langoni, C. (1974): Distribuição de Renda e Desenvolvimento Econômico no Brasil. Editora FGV, terceira edição, 2005.

Leff, N. e A. Delfim Netto (1966): "Import Substitution. Foreign Investment, and International Disequilibrium in Brazil". The Journal of Development Studies; 2(3).

Lisboa, M. (2019): "A Estranha Economia da USP, uma Historiadora Fora do Lugar, um Estatístico que Admirava Marshall e Antonio Delfim Netto: Um preâmbulo para as imensas contribuições de Affonso Celso Pastore". Texto apresentado no seminário em homenagem aos 80 anos de Affonso Celso Pastore.

Lisboa, M. e Z. Latif (2014): “Crescimento e Democracia no Brasil”. A Via Democrática, Simon Schwartzman, org. Editora Elsevier.

Pessôa, S. e M. Lisboa (2019): “Affonso Celso Pastore: Debate permanente com base na evidência empírica". Texto apresentado no seminário em homenagem aos 80 anos de Affonso Celso Pastore.

Restuccia, D. e R. Rogerson (2017): "The Causes and Costs of Misallocation". Journal of Economic Perspectives; 31(3).

Veloso, F., A. Vilella e F. Giambiagi (2008): "Determinantes do "Milagre" Econômico Brasileiro (1968-1973): uma análise empírica". Revista Brasileira de Economia, 62(2). 